American Journal of Biotechnology and Biochemistry 4 (2): 61-72, 2008

ISSN 1553-3468

(C) 2008 Science Publications

\title{
The Autistic Phenotype Exhibits a Remarkably Localized Modification of Brain Protein by Products of Free Radical-Induced Lipid Oxidation
}

\author{
${ }^{1}$ Teresa A. Evans, ${ }^{1}$ Sandra L. Siedlak, ${ }^{2}$ Liang Lu, ${ }^{3}$ Xiaoming Fu, ${ }^{3}$ Zeneng Wang, ${ }^{4}$ Woody R. McGinnis, \\ ${ }^{5}$ Evelyn Fakhoury, ${ }^{6}$ Rudy J. Castellani, ${ }^{3}$ Stanley L. Hazen, ${ }^{5}$ William J. Walsh, ${ }^{5}$ Allen T. Lewis, ${ }^{2}$ Robert G. \\ Salomon, ${ }^{1}$ Mark A. Smith, ${ }^{1,7}$ George Perry and ${ }^{1}$ Xiongwei Zhu \\ Departments of ${ }^{1}$ Pathology and ${ }^{2}$ Chemistry, Case Western Reserve University, Cleveland, OH 44106; \\ ${ }^{3}$ Department of Cardiovascular Medicine and Center for Cardiovascular Diagnostics and \\ Prevention, Cleveland Clinic Foundation, Cleveland, Ohio 44195; ${ }^{4}$ Ashland, OR 97520; ${ }^{5}$ Pfeiffer \\ Treatment Center, Health Research Institute, Warrenville, IL 60555; ${ }^{6}$ Department of Pathology, \\ University of Maryland, Baltimore, MD 21201; ${ }^{7}$ College of Sciences, University of Texas at San Antonio, \\ San Antonio, TX 78249
}

\begin{abstract}
Oxidative damage has been documented in the peripheral tissues of autism patients. In this study, we sought evidence of oxidative injury in autistic brain. Carboxyethyl pyrrole (CEP) and iso[4]levuglandin (iso[4]LG) $\mathrm{E}_{2}$-protein adducts, that are uniquely generated through peroxidation of docosahexaenoate and arachidonate-containing lipids respectively, and heme oxygenase-1 were detected immunocytochemically in cortical brain tissues and by ELISA in blood plasma. Significant immunoreactivity toward all three of these markers of oxidative damage in the white matter and often extending well into the grey matter of axons was found in every case of autism examined. This striking threadlike pattern appears to be a hallmark of the autistic brain as it was not seen in any control brain, young or aged, used as controls for the oxidative assays. Western blot and immunoprecipitation analysis confirmed neurofilament heavy chain to be a major target of CEP-modification. In contrast, in plasma from 27 autism spectrum disorder patients and 11 age-matched healthy controls we found similar levels of plasma CEP (124.5 \pm 57.9 versus $110.4 \pm 30.3 \mathrm{pmol} / \mathrm{mL})$, iso[4] $\mathrm{LGE}_{2}$ protein adducts $(16.7 \pm 5.8$ versus $13.4 \pm 3.4 \mathrm{nmol} / \mathrm{mL})$, anti-CEP $(1.2 \pm 0.7$ versus $1.2 \pm 0.3)$ and anti-iso[4]LGE autoantibody titre $(1.3 \pm 1.6$ versus $1.0 \pm 0.9)$, and no differences between the ratio of $\mathrm{NO}_{2} \mathrm{Tyr} / \mathrm{Tyr}$ $(7.81 \mathrm{E}-06 \pm 3.29 \mathrm{E}-06$ versus $7.87 \mathrm{E}-06 \pm 1.62 \mathrm{E}-06)$. These findings provide the first direct evidence of increased oxidative stress in the autistic brain. It seems likely that oxidative injury of proteins in the brain would be associated with neurological abnormalities and provide a cellular basis at the root of autism spectrum disorders.
\end{abstract}

Keywords: autistic disorder, oxidative damage, lipid peroxidation, carboxyethylpyrrole, iso[4]levuglandin $\mathrm{E}_{2}$, heme oxygenase

\section{INTRODUCTION}

Autism, first described in 1943 by Kanner ${ }^{[1]}$ and officially recognized in $1980^{[2]}$, is a neurodevelopmental disorder characterized by decreased levels of social interaction, lack of imaginative play or language skills and increases in repetitive activities in children, usually presented before the age of $3^{[2]}$. Autism and closely related pervasive developmental disorders (PDDs) are referred to as autism spectrum disorders (ASD) that corresponds to what the Diagnostic and Statistical Manual of Mental Disorders (DSM-IV) refers to collectively as PDD. Approximately $80 \%$ of children with autism also have some degree of mental retardation and most do not reach independence as adults ${ }^{[3]}$. The most recent epidemiological studies of autism report rates of up to one in 150 children with $\mathrm{ASD}^{[4]}$. The need for a better understanding of this disease is heightened by the concern that autism is increasing in frequency.

Although there is no known unique cause of autism, a number of factors have been implicated in the

Corresponding Author: George Perry and Xiongwei Zhu, Department of Pathology, Case Western Reserve University, Cleveland, OH 44106 
pathogenesis of autism, including genetic, recognized that $5-10 \%$ of autistic spectrum disorders are classified with chromosomal abnormalities, and even greater numbers may be related to one or several identified susceptibility $\operatorname{loci}^{[5]}$. There are high concordance rates in siblings of autistic probands, as well as in monozygotic twins ${ }^{[6]}$. Hence it has now become generally accepted that autism has a biological basis.

Children with autism often present with abnormal immune and digestive systems, such as inflammation of the bowel, and changes in digestive enzymes, and often suffer from bowel problems and constipation, and occasionally liver problems ${ }^{[7]}$. The cause of these changes is not entirely known. Similarly increased NO levels in red blood cells and higher antioxidant enzyme activity as well as zinc deficiency and copper excess in plasma from autistic children are noted ${ }^{[8-10]}$. Treatment with vitamin $\mathrm{C}$, carnosine, or vitamin B6 leads to significant improvement in autistic children compared with placebo ${ }^{[11-13]}$, and this may be a result of protection against oxidative injury.

Autism is apparently a disorder of prenatal and postnatal brain development. The gross brain changes reported include changes in brain volume in young children, later returning to normal volume, using head circumference measurements. Thus, very large differences between autistic and normal children are evident at early ages, but differences are not seen in adult cases. Decreased gray matter volumes are also sometimes noted $^{[14]}$. There is substantial evidence from neuroimaging studies that dysfunctions in the cerebellum and possibly the temporal lobe and association cortex result in autistic symptoms ${ }^{[15]}$. There is a reduction in granule and Purkinje cell density in the neocerebellum $^{[16]}$ and alterations in neuronal size, density and dendritic branching in the cerebellum and limbic structures of autistic individuals ${ }^{[17]}$. Significantly fewer neurons in the autistic amygdala overall and in its lateral nucleus are noted ${ }^{[18]}$, suggesting neuronal loss occurs in more than one brain area. The corpus callosum is smaller, and neuroimaging suggests under connectivity of brain areas ${ }^{[19]}$. However, it is unclear what causes these abnormalities in the disease.

In view of some evidence for elevated oxidative stress in peripheral tissues from autistic patients and the sensitivity of brain to oxidative injury, we postulated that oxidative stress plays a role in the brain abnormalities in autism. In this regard, impaired mitochondrial function in autism is suggested by magnetic resonance imaging that showed decreased ATP levels in autistic brain. Furthermore, elevated environmental, immunological and neurological. It is levels of lactate, pyruvate, and ammonia, and lower levels of carnitine are documented in autistic children $^{[20]}$. Indeed, mitochondrial abnormalities, a potential source of elevated oxidative stress, were reported in autistic case studies ${ }^{[21]}$.

A major cause of damage to cells results from reactive oxygen species (ROS)-induced alteration of proteins and DNA by reactive electrophilic oxidation products from polyunsaturated fatty acyls in membrane lipids. Oxidative stress and ROS have been implicated in disease states such as Alzheimer's disease, Parkinson's disease, cancer, atherosclerosis, age-related macular degeneration (AMD), and aging. Under normal conditions, ROS are cleared from the cell by the action of superoxide dismutase (SOD), catalase, or glutathione peroxidase (GPx). SOD, MnSOD in the mitochondria and $\mathrm{CuZnSOD}$ in the cytoplasm, removes superoxide anion by converting it into hydrogen peroxide $\left(\mathrm{H}_{2} \mathrm{O}_{2}\right)$. Catalase and GPx reduce $\mathrm{H}_{2} \mathrm{O}_{2}$ to water. In the presence of unbound $\mathrm{Cu}$, under certain conditions, SOD can promote oxidative injury owing to a $\mathrm{Cu}$ catalyzed, Haber-Weiss, reaction of $\mathrm{H}_{2} \mathrm{O}_{2}$ to generate $\bullet \mathrm{OH}$, a potent ROS. Statistically significant elevations in $\mathrm{ZnCuSOD}$ were documented in erythrocytes and in platelets of autistic individuals compared with controls $^{[22]}$. Plasma concentrations of reduced glutathione $(\mathrm{GSH})$ are generally lower $(4.1 \pm 0.5$ $\mu \mathrm{mol} / \mathrm{L})$ for autistics compared with healthy controls $(7.6 \pm 1.4 \mu \mathrm{mol} / \mathrm{L}), p<0.001^{[23,24]}$. These abnormally low levels of plasma GSH could favor oxidative stress because GSH is a cofactor for glutathione peroxidase (GPx), an antioxidant enzyme. Furthermore, severely depressed levels of GPx $(-44.4 \%)$ are found in erythrocytes of autistic individuals compared with controls ${ }^{[25,26]}$. As a result, the $\mathrm{H}_{2} \mathrm{O}_{2}$ formed by the action of SOD would not be efficiently removed owing to diminished levels of GPx. The imbalance is exacerbated by the low plasma GSH levels found in ASD patients, because GSH is a cosubstrate needed for the GPx-promoted reduction of $\mathrm{H}_{2} \mathrm{O}_{2}$. Lipid peroxidation products in the urine are now considered a biomarker for autism ${ }^{[27]}$.

In this study, to substantiate the role of oxidative stress in autism brain, we used antibodies against two distinct lipid-derived oxidative protein modifications. One of these, carboxyethyl pyrrole (CEP) is derived exclusively from free radical-induced oxidative cleavage of docosahexaenoates, e.g., the docohexaenoic acid (DHA) ester of 2-lysophosphatidylcholine (PC) DHA-PC, to afford HOHA-PC that then reacts with 
Am. J. Biochem. \& Biotech., 4 (2): 61-72, 2008

protein to generate CEP modifications of the $\varepsilon$-amino groups of lysyl residues (Fig. 1) ${ }^{[28]}$.

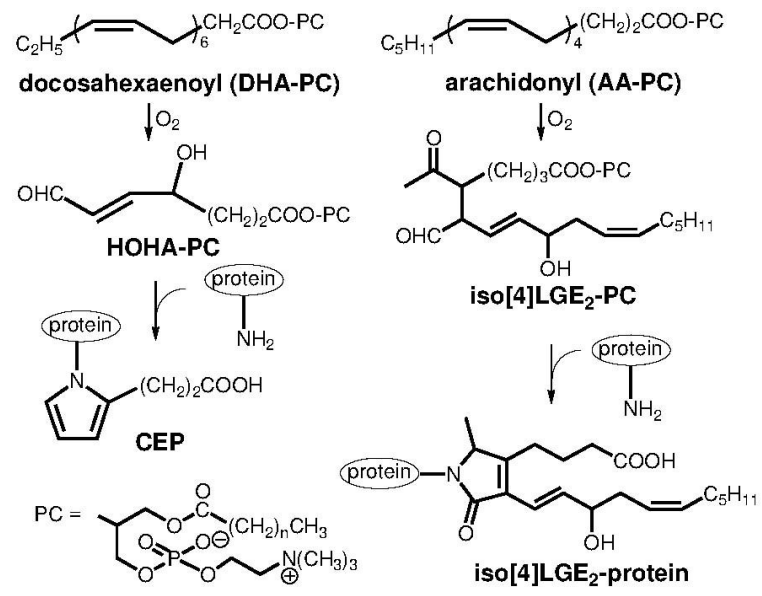

Fig. 1: Generation of CEP and iso[4] $\mathrm{LGE}_{2}$-protein adducts.

Prominent elevations of CEP levels were noted previously in retinas of individuals with AMD. We also used antibodies against iso[4] $\mathrm{LGE}_{2}$-protein adducts that arise exclusively through free radical-induced cyclooxygenation of arachidonates, e.g., the arachidonic acid (AA) ester AA-PC, and subsequent adduction of an intermediate iso[4] $\mathrm{LGE}_{2}-\mathrm{PC}$ with protein (Fig. 1). Iso[4] $\mathrm{LGE}_{2}$-protein adducts are indelible markers that provide a cumulative index for oxidative injury, such as that associated with inflammation $^{[29-32]}$.

ASD seems to arise from environmental factors interacting with a genetic predisposition. It often occurs in conjunction with a family history of autoimmune diseases ${ }^{[33]}$. As mentioned above, autistic patients often have immune abnormalities. Autoantibodies IgG, IgM, $\operatorname{IgE}$ and $\operatorname{IgA}$ against brain proteins are present in ASD patients ${ }^{[34]}$. Inflammatory over-activation is suggested by the observation that many autistic children appear to produce excessive amounts of TNF $\alpha$ and other proinflammatory cytokines ${ }^{[33]}$. IgG anti-brain autoantibodies were present in $27 \%$ of sera from children with ASD compared with $2 \%$ from healthy children. IgM autoantibodies were present in $36 \%$ of sera from children with ASD compared with $0 \%$ of control sera $^{[35]}$. In another study, sera from 40 healthy subjects and 40 autistic children were analyzed for the presence of $\operatorname{IgG}$, IgM, and IgA antibodies against nine neuron-specific antigens and three encephalitogenic and cross-reactive proteins. Only $7.5-10 \%$ of controls had IgA, IgG or IgM antibodies against neurofilaments compared to $37.5 \%, 50 \%$ and $57.5 \%$ of autistic subjects $^{[28]}$. The possible operation of an immune response against altered self proteins, has not been examined. Our previous studies demonstrated significantly elevated levels of CEP epitopes and the corresponding autoantibodies in the blood of AMD patients compared with healthy age and sex matched controls $^{[36]}$. We sought to determine whether levels of CEP epitopes and autoantibodies in the blood of ASD are also elevated as it is in blood from AMD patient.

We now report that CEP and iso[4] $\mathrm{LGE}_{2}$-protein adducts in cortical brain tissues are a hallmark of autism, and more specifically, we demonstrated neurofilament heavy chain (NFH) to be a major protein target for CEP-modification. To our knowledge, this is the first direct evidence of increased oxidative stress in the autistic brain. We also compared levels of CEP and iso[4] $\mathrm{LGE}_{2}$-protein adducts in plasma from patients with documented ASD with age-matched healthy controls. Anti-CEP, anti-iso[4]LGE 2 -protein, autoantibodies were also measured. In addition, since recent studies proposed a possible participation of enhanced nitrative stress in AMD pathologies ${ }^{37]}$, levels of protein bound nitrotyrosine in plasma from ASD and normal controls were compared in this study by stable isotope dilution tandem mass spectrometry. No significant elevations in the levels of any of these markers of oxidative injury were detected in the plasma of patients with ASD. However, an unanticipated strong elevation of plasma iso[4] $\mathrm{LGE}_{2}$ immunoreactivity levels was found in ASD patients born prematurely compared with ASD patients with no birth events or other birth events.

\section{MATERIALS AND METHODS}

Brain Samples: Autopsy brain samples from children with autism were obtained from the University of Maryland Brain Bank. Control cases of similarly age matched as well as older ages were also sampled. Table 1 gives the case information. Initial studies were analyzed using an array of slides prepared from formalin-fixed tissue, consisting of 5 cases of autism and 5 controls, with small core samples blocked simultaneously of cerebellum, white matter and cortical area (a gift from Dr. Charles Eberhart from Johns Hopkins University, coordinated graciously through the Autism Tissue Program). After interesting results were obtained with these samples, blocks of larger cortical (Brodmann area 39) as well as hippocampal samples were analyzed (NICHD Brain and Tissue Bank for Developmental Disorders at the University of Maryland). Also from this source, frozen tissue was obtained from one case of autism, which was compared with young control cases from the Case Western Reserve University Brain Bank for protein and biochemical analysis.

Immunohistochemistry: $6 \mu \mathrm{m}$ sections were deparaffinized in xylene and rehydrated in graded alcohol, the endogenous peroxidase activity eliminated 
Am. J. Biochem. \& Biotech., 4 (2): 61-72, 2008

by incubation in $3 \%$ hydrogen peroxide in methanol for $30 \mathrm{~min}$, and finally rinsed in Tris buffered saline. Sections were blocked in $10 \%$ normal goat serum (NGS) for $30 \mathrm{~min}$ followed by overnight incubation with primary antibody in $1 \%$ NGS at $4^{\circ} \mathrm{C}$ in a humidified chamber. Staining was completed using the peroxidase-anti-peroxidase procedure with 3,3diaminobenzidine (DAB) as chromagen, and sections were dehydrated and mounted with permount. Antisera recognizing heme oxygenase-1 (Stressgen), CEP and iso[4] $\mathrm{LGE}_{2}$-protein adducts (available in our laboratories) and monoclonal antibodies against neurofilament protein (Sternberger Meyer Inc.) were used. Antibody specificity for CEP was confirmed by performing an adsorption experiment with its corresponding antigen. Diluted antibody was incubated overnight with $20 \mu \mathrm{g}$ of CEP-KLH and applied to an adjacent section with antibody alone. Omission of primary antibody was also performed as a negative control (data not shown).

\begin{tabular}{|c|c|c|c|c|}
\hline Autism & Age & PMI (hr) & Cause of Death & Tissue \\
\hline 1 & 5.6 & 39 & Drowning & Cortex/Array \\
\hline 2 & 7.8 & 14 & $\begin{array}{l}\text { Multi-system } \\
\text { organ failure }\end{array}$ & $\begin{array}{l}\text { Frozen } \\
\text { Cortex/Array }\end{array}$ \\
\hline 3 & 8 & 23 & Drowning & Hippocampus \\
\hline 4 & 8.5 & 24 & Drowning & $\begin{array}{l}\text { Hippocampus } \\
\text { /Array }\end{array}$ \\
\hline 5 & 8.8 & 16 & Drowning & Hippocampus \\
\hline 6 & 9 & 39 & Drowning & Hippocampus \\
\hline 7 & 9.3 & 13 & Drowning & Cortex/Array \\
\hline 8 & 10 & 24 & Smoke inhalation & Cortex/Array \\
\hline 9 & 12 & 23 & Drowning & Hippocampus \\
\hline Control & Age & $P M I(h r)$ & Cause of Death & Tissue \\
\hline 1 & 1.8 & 20 & Biliary atresia & Hippocampus \\
\hline 2 & 4 & 7 & $\begin{array}{l}\text { Congenital heart } \\
\text { disease }\end{array}$ & Hippocampus \\
\hline 3 & 5 & 20 & Drowning & Array \\
\hline 4 & 6 & 18 & $\begin{array}{l}\text { Accident/ } \\
\text { multiple injuries }\end{array}$ & Array \\
\hline 5 & 8 & 36 & $\begin{array}{l}\text { Head trauma/ } \\
\text { hemorrhage }\end{array}$ & Array \\
\hline 6 & 9 & 20 & Asthma & Array \\
\hline 7 & 11 & 19 & Drowning & Array \\
\hline 8 & 11 & 12 & Leukemia & Hippocampus \\
\hline 9 & 14 & 6.5 & $\begin{array}{l}\text { Embryonic } \\
\text { rhabdo- } \\
\text { myosarcoma }\end{array}$ & Hippocampus \\
\hline 10 & 17 & 15 & Gunshot & Hippocampus \\
\hline 11 & 17 & 16 & Drowning & Hippocampus \\
\hline 12 & 19 & 42 & $\begin{array}{l}\text { Sickle cell } \\
\text { anemia }\end{array}$ & Hippocampus \\
\hline 13 & 31 & 4 & Cystic fibrosis & Hippocampus \\
\hline 14 & 43 & N/A & $\begin{array}{l}\text { Anoxic } \\
\text { encephalopathy }\end{array}$ & Hippocampus \\
\hline 15 & 64 & 2 & Aortic hematoma & Hippocampus \\
\hline 16 & 68 & 5 & Breast carcinoma & Hippocampus \\
\hline 17 & 72 & N/A & Alzheimer & Hippocampus \\
\hline 18 & 83 & 37 & Alzheimer & Hippocampus \\
\hline 19 & 87 & 7 & Alzheimer & Hippocampus \\
\hline
\end{tabular}

Western blot analysis and immunoprecipitation: Frozen cortical tissue samples were collected from one case of autism (age 8 years) and 1 controls (age 17 years). Tissue was homogenized in $10 \mathrm{vol}$. of $20 \mathrm{mM}$ Tris- $\mathrm{HCl}$ (pH 7.5), $150 \mathrm{mM} \mathrm{NaCl}, 1 \mathrm{mM} \mathrm{Na}{ }_{2}$ EDTA, 1 mM EGTA, $1 \%$ Triton, $2.5 \mathrm{mM}$ sodium pyrophosphate, $1 \mathrm{mM} \beta$-glycerophosphate, $1 \mathrm{mM} \mathrm{Na} \mathrm{VO}_{4}, 1 \mu \mathrm{g} / \mathrm{ml}$ leupeptin, $1 \mathrm{mM}$ PMSF (lysis buffer), assayed for protein concentration using BCA (Pierce), and proteins were separated using SDS gel electrophoresis and transferred to immobilon (Millipore). After blocking in $10 \%$ dry milk in TBS-tween, anti-CEP was applied overnight, the blots rinsed in TBS-tween 4 times for 5 minutes each and then incubated in peroxidase labeled secondary antibody. Detection was performed using enhanced chemiluminescence (Millipore).

For immunoprecipitation, the homogenate was precleared by incubating with Protein G-agarose (Roche) at $4^{\circ} \mathrm{C}$ for 2 hours, followed by centrifugation at $10,000 \mathrm{rpm}$ for 10 minutes at $4^{\circ} \mathrm{C}$. anti-CEP was added to the supernatant and incubated at $4^{\circ} \mathrm{C}$ for 4 hours with end-over-end rotation, followed by the addition of Protein G-agarose and incubated overnight. Following centrifugation at $10,000 \mathrm{rpm}$ for 10 minutes at $4{ }^{\circ} \mathrm{C}$, the supernatant was carefully aspirated and discarded. The pellet was washed 4 times with lysis buffer, and the sample boiled for 10 minutes prior to SDS-PAGE. For immunoblot analysis of the precipitate, $10 \mu \mathrm{l}$ of bead slurry was used for precipitation of 500 $\mu \mathrm{g}$ of protein homogenate. The entire precipitate was loaded in one lane, and proteins were separated by SDS-PAGE followed by transfer onto Immobilon-P (Millipore, Bedford, MA). SMI32 monoclonal antibody was used to detect $\mathrm{NFH}^{[38]}$.

Human plasma: Blood samples were obtained by phlebotomists at the Institute's Pfeiffer Treatment Center. Eligibility for the study was based on a diagnosis of ASD, as defined by DSM-IV. Subjects with questionable diagnoses and patients with comorbidity for seizures, and birth anoxia were excluded. In total, 27 autistic subjects and 11 healthy control subjects were recruited for the study. Plasma (5 $\mathrm{mL}$ ) was collected in $7 \mathrm{~mL}$ lavender top vacutainer tubes with EDTA. The tube was then gently inverted 56 times to distribute the anticoagulant. After spinning in a refrigerated centrifuge $\left(4^{\circ} \mathrm{C}\right)$ at $3000 \mathrm{rpm}$ for 15 minutes, plasma $(2.0 \mathrm{~mL})$ was transferred (careful to avoid the buffy coat) into a $15 \mathrm{~mL}$ Falcon tube. A BHT/ethanol solution was prepared by combining BHT $(0.04408 \mathrm{~g})$ with ethanol $(10 \mathrm{~mL})$. If refrigerated, the BHT solution is good for 3 weeks. Then $10 \mu \mathrm{L}$ of BHT/ethanol solution ( $5 \mu \mathrm{L} / \mathrm{mL}$ plasma) and $20 \mu \mathrm{L}$ of 
protease inhibitor cocktail kit $(10 \mu \mathrm{L} / \mathrm{mL}$ plasma, Sigma, Cat. P8340) were added to the plasma and mixed by gentle inversion (do not vortex) of the tube 56 times. The plasma was finally aliquoted $(250 \mu \mathrm{L})$ into 8 prelabeled screw-top microfuge tubes that were gently flushed with argon and sealed with screw caps. The samples were then quench frozen in liquid nitrogen by placing the 8 vials into a Scienceware Round Bubble Rack (Fisher, Cat. 14-792-14 Bel-Art, fishersci.com) and then immersing the bottom of the rack and the tubes into liquid nitrogen in a Nalgene polyethylene Dewar flask for 1 minute. The vials were stored in Fiberboard Storage Boxes (Fisher, Cat. 11-678-24A, fishersci.com) with Fiberboard Box Dividers (Fisher, Cat. 11-678-24C, fishersci.com) in dry ice for transport or at $-80^{\circ} \mathrm{C}$.

ELISA: A competitive enzyme-linked immunosorbent assay (ELISA) of plasma from ASD and healthy controls was performed as described previously for CEP and iso[4]LGE 2 immunoreactivities ${ }^{[28]}$. For CEP immunoreactivity, CEP-BSA was used as a coating agent and CEP-HSA was used as a standard. The initial concentration of CEP-HSA was $16.7 \mathrm{nmol} / \mathrm{mL}$. For iso[4] $\mathrm{LGE}_{2}$ immunoreactivity, iso[4] $\mathrm{LGE}_{2}$-BSA was used as a coating agent and iso[4] $\mathrm{LGE}_{2}$-HSA was used as a standard. The initial concentration of iso[4] $\mathrm{LGE}_{2}-$ HSA was $810 \mathrm{nmol} / \mathrm{mL}$. A dilution factor of 0.2 was employed for standard and samples. Eight serial dilutions for standard, five serial dilutions of samples were performed.

A direct ELISA ${ }^{[39]}$ was performed for anti-CEP and anti-iso[4]LGE $\mathrm{LG}_{2}$ autoantibodies. Absorbance values were measured on a Bio Rad Microplate Reader using dual wavelength (405 $\mathrm{nm}$ to read the plate and $650 \mathrm{~nm}$ as a reference). The plates were coated with CEP-BSA

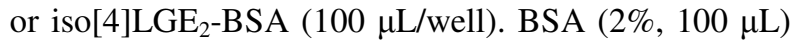
was added to the corresponding blank wells. The plates were incubated for $1 \mathrm{~h}$ at $37^{\circ} \mathrm{C}$, washed with PBS (10 $\mathrm{mM}, 300 \mu \mathrm{L}) 3$ times, and blocked with $1 \%$ chicken egg ovalbumin $(\mathrm{CEO}, 300 \mu \mathrm{L})$ for $1 \mathrm{~h}$ at $37^{\circ} \mathrm{C}$. After washing once with $0.1 \%$ CEO plus $0.05 \%$ Tween 20 $(300 \mu \mathrm{L})$, the plates were loaded with plasma, diluted 20 times in $0.2 \%$ CEO plus $0.05 \%$ Tween 20 , and then incubated for $1 \mathrm{~h}$ at room temperature. The plates were then washed 3 times with $0.1 \%$ CEO plus $0.05 \%$ Tween $20(300 \mu \mathrm{L})$, and incubated $1 \mathrm{~h}$ at room temperature with alkaline phosphatase conjugated goat anti-human IgG (Sigma-Aldrich, Milwaukee, WI, Cat. Sigma A8542), which was diluted 1:2000 with $1 \%$ CEO plus $0.05 \%$ Tween $20(100 \mu \mathrm{L})$. After washing with $0.1 \%$ CEO (3 x $300 \mu \mathrm{L})$, a solution of $p$-nitrophenyl phosphate in $0.2 \mathrm{M}$ Tris buffer $(1.0 \mathrm{mg} / \mathrm{mL}, 100 \mu \mathrm{L}$,
Sigma-Aldrich, Milwaukee, WI, Cat. Sigma N1891) was added. The absorbance was read at $405 \mathrm{~nm}$ with reference at $650 \mathrm{~nm}$ after incubation at room temperature for 30 minutes. The titer was defined as the ratio of plasma binding to antigen (A) vs. binding to BSA blank $\left(\mathrm{A}_{0}\right)$.

Protein hydrolysis: Plasma samples were delipidated and desalted using two sequential extractions with a single phase mixture of $\mathrm{H}_{2} \mathrm{O} /$ methanol/ $\mathrm{H}_{2} \mathrm{O}$-saturated diethyl ether $(1: 3: 8 \mathrm{v} / \mathrm{v} / \mathrm{v})$. Oxidized tyrosine standards, ${ }^{13} \mathrm{C}_{6}$-ortho-tyrosine (o-Tyr), ${ }^{13} \mathrm{C}_{6}$-meta-tyrosine (mTyr), ${ }^{13} \mathrm{C}_{6}$-nitro-tyrosine (Nitro-Tyr), ${ }^{13} \mathrm{C}_{6}$-chlorotyrosine (Cl-Tyr), ${ }^{13} \mathrm{C}_{6}$-bromo-tyrosine (Br-Tyr) (2 pmol each) and universal labeled tyrosine, ${ }^{13} \mathrm{C}_{9^{-}}{ }^{15} \mathrm{~N}-$ tyrosine $(2 \mathrm{nmol})$ were added to protein pellets. Samples were hydrolyzed in degassed $4 \mathrm{M}$ methane sulfonic acid $(500 \mu \mathrm{L})$ supplemented with $1 \%$ phenol for $24 \mathrm{~h}$ at $110^{\circ} \mathrm{C}$ under argon atmosphere. Amino acid hydrolysates were resuspended in $0.1 \%$ trifluoroacetic acid $(2 \mathrm{~mL})$ and applied to mini solid-phase $\mathrm{C} 18$ extraction columns (Supelclean LC-C18 SPE minicolumn, $3 \mathrm{ml}$; Supelco, Inc., Bellefone, PA) preequilibrated with $0.1 \%$ trifluoroacetic acid. Following sequential washes with trifluoroacetic acid $(2 \mathrm{ml}$, $0.1 \%$ ), oxidized tyrosines and tyrosine were eluted with $2 \mathrm{ml}$ of $30 \%$ methanol in $0.1 \%$ trifluoroacetic acid, dried under vacuum, and then analyzed by mass spectrometry as described below. Synthetic $\left[{ }^{13} \mathrm{C}_{6}\right]-$ labeled 3-nitrotyrosine was used as internal standard for quantification of natural abundance 3-nitrotyrosine. Simultaneously, a universal labeled precursor amino acid, $\left[{ }^{13} \mathrm{C}_{9},{ }^{15} \mathrm{~N}_{1}\right]$ tyrosine, was added, permitting potential intrapreparative formation of nitro[ $\left[{ }^{13} \mathrm{C}_{9}\right.$, ${ }^{15} \mathrm{~N}_{1}$ ]tyrosine to be routinely monitored and shown to be negligible (i.e., $<5 \%$ of the level of the natural abundance product observed). Results are normalized to the content of the precursor amino acid tyrosine (i.e., nitrotyrosine/tyrosine, micromoles/moles), which was monitored within the same injection.

Mass spectrometric analysis of nitrotyrosine: Protein-bound nitrotyrosine in plasma from ASD and healthy controls was quantified by stable isotope dilution LC/MS/MS as described ${ }^{[40]}$. Nitrotyrosine in lysates were analyzed by HPLC with on-line electrospray ionization tandem mass spectrometry (LC/ESI/MS/MS) using stable isotope dilution methodology on a triple quadrupole mass spectrometer (API 365; Applied Biosystems, Foster City, CA) with Ionics EP 10+ upgrade (Ionics, Concord, Ontario, CA) interfaced to a Cohesive Technologies (Franklin, MA) Aria LX Series HPLC multiplexing system. Samples 

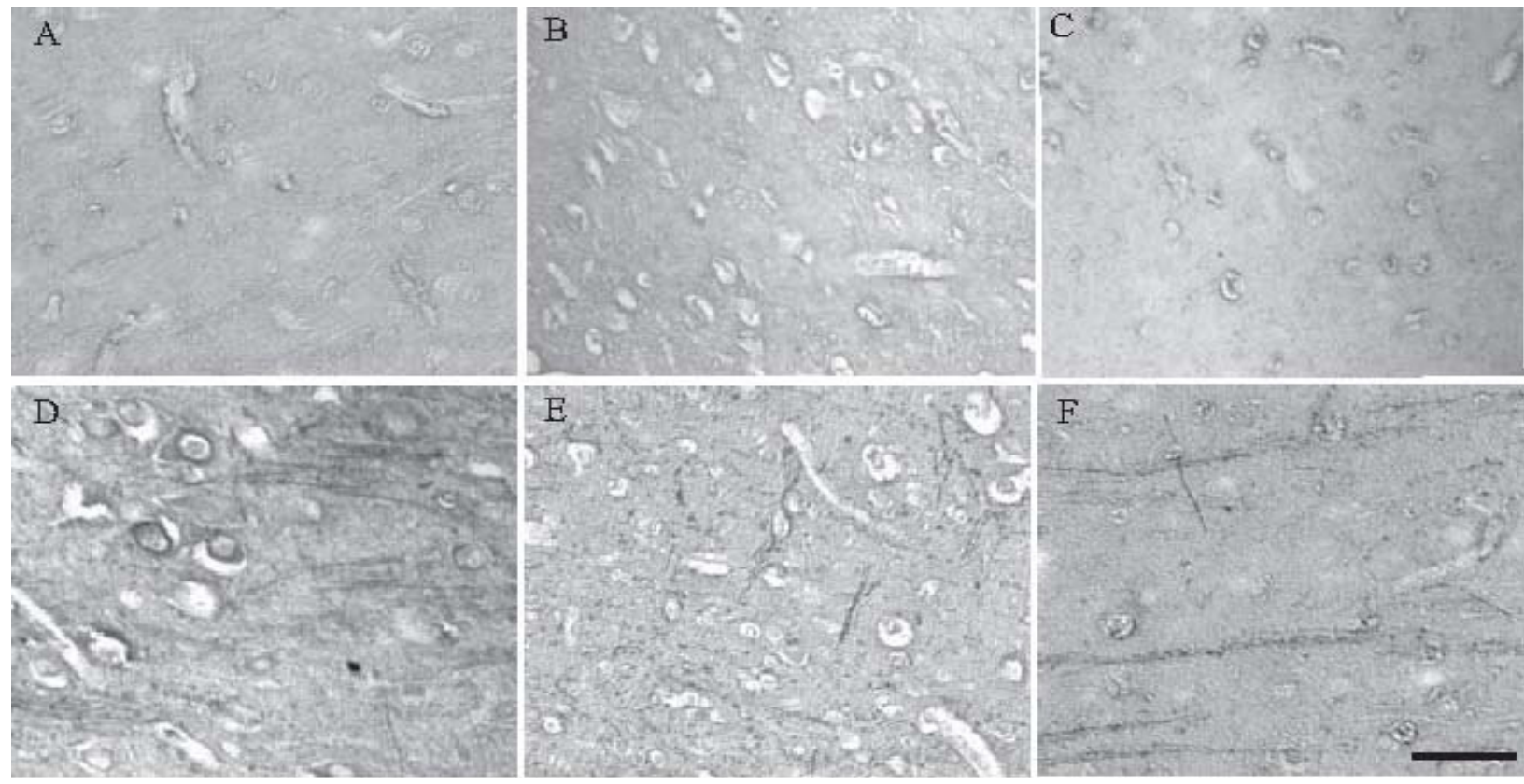

Fig. 2: CEP-modified protein is readily detected in the brains of all autism cases while no specific labeling is seen in controls. Representative cases of autism aged 9, 7, and 5 years (D, E, F) and controls aged 5, 6, and 11 years $(\mathrm{A}, \mathrm{B}, \mathrm{C})$ are shown. In some autism cases, CEP is also present in neuronal cell bodies (D). Scale bar $=50$ $\mu \mathrm{m}$.

were suspended in equilibration solvent $\left(\mathrm{H}_{2} \mathrm{O}\right.$ with $0.1 \%$ formic acid) and injected onto an Ultrasphere $\mathrm{C} 18$ column (Phenominex, $5 \mu \mathrm{m}, 2.0 \times 150 \mathrm{~mm}$ ). LTyrosine and its oxidation products were eluted at a flow rate of $0.2 \mathrm{~mL} / \mathrm{min}$ using a linear gradient generated against $0.1 \%$ formic acid in acetonitrile $\mathrm{pH}$ 2.5 , as the second mobile phase. Analytes were monitored in positive ion mode with full scan product ion MS/MS at unit resolution. Response was optimized with a spray voltage setting of $5 \mathrm{kV}$. The heated capillary voltage was set at $10 \mathrm{~V}$ and the temperature to $350^{\circ} \mathrm{C}$. Nitrogen was used both as sheath and auxiliary gas, at a flow rate of 12 and 8 psi, respectively. The precursor ion isolation width was 1.0 and 3.0 for nitrotyrosine and tyrosine, respectively. The analyte abundance was evaluated by measuring the chromatographic peak areas of selected product ions extracted from the full scan total ion chromatogram, according to the corresponding ion trap product ion spectra. The ions monitored for each analyte were: 3nitro $\left[{ }^{12} \mathrm{C}_{6}\right]$ tyrosine (mass-to-charge-ratio $(\mathrm{m} / \mathrm{z})$ $227 \rightarrow 181) ; 3$-nitro $\left[{ }^{13} \mathrm{C}_{6}\right]$ tyrosine $(\mathrm{m} / \mathrm{z} \quad 233 \rightarrow 187)$; 3nitro $\left[{ }^{13} \mathrm{C}_{9}{ }^{15} \mathrm{~N}_{1}\right]$ tyrosine $(\mathrm{m} / \mathrm{z}, 237 \rightarrow 190)$.

The maximum ion injection time was $100 \mathrm{~ms}$; a scan rate was used that permitted a minimum sampling rate of at least 9 points/chromatographic peak. For all analyses, results were normalized to the content of the precursor amino acid L-tyrosine, which was monitored within the same injection of each oxidized amino acid.

Statistical analyses: ASD and normal controls were compared using CEP, iso[4]LGE 2 protein adducts, anti$\mathrm{CEP}$, anti-iso[4] $\mathrm{LGE}_{2}$ antibodies and nitroTyr/Tyr ratio. $\mathrm{P}$-values were calculated by independent t-test and analysis of variance (ANOVA) using Microsoft Excel 2003 for Windows. The significance of group comparisons was corrected for the effect of repeated measures. Correlations between measured parameters were ascertained using pair-wise comparisons by linear regression and were performed using JMP 5.12 (SAS Institute, Cary NC). Data were expressed as mean \pm SD. Statistical significance was defined as $p$ less than 0.05 .

\section{RESULTS}

The tissue array samples were very useful in obtaining preliminary data. Prominent staining by antiCEP antibody was observed in all 5 cases of autism, and not in any of the control specimens. Fig. 2 shows representative cortical staining patterns from 3 of the 
autism cases aged 9, 7, and 5 years (Fig. 2D, E, F) and 3 control cases aged 5, 6 and 11 years (Fig. 2A, B, C) from the tissue array samples. Significant labeling in the white matter and often extending well into the grey matter of axons was found in every case of autism examined. Often, cell bodies were also labeled (Fig. 2D). This pattern of staining was not seen in any control case, age-matched or even older cases. Thus, this pattern of staining is apparently a hallmark of autistic brain.

Strong staining in the white matter and grey matter in a representative autism case is readily apparent in the larger tissue specimens viewed at lower magnification (Fig. 3B) in contrast with a comparable section of control brain (Fig. 3A). Adjacent serial sections of another case of autism show that the cellular localization of CEP (Fig. 3C) is greatly reduced following adsorption with its antigen (Fig. 3D), confirming the specificity of the antibody. Other well characterized markers of oxidative damage are also localized to similar structures in many cases of autism. In autism brain, heme oxygenase-1 (Fig. 4E) and iso[4]LGE 2 (Fig. 4F) accumulates within the same processes as CEP- modified proteins (Fig. 4D), compared to control cases (Fig. 4A, B, C) stained for the same markers.

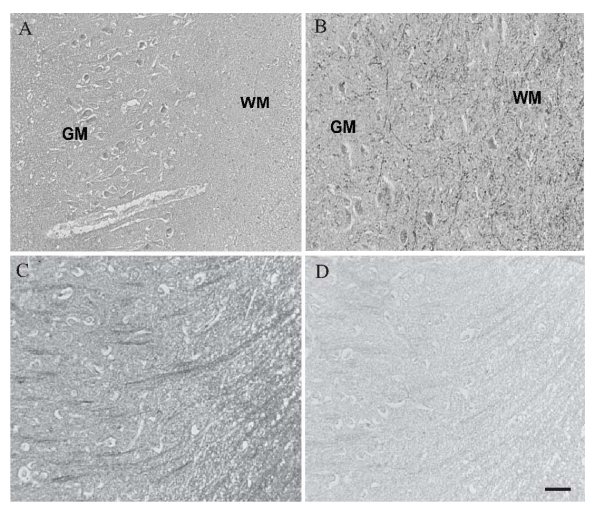

Fig. 3: At lower magnification, the accumulation of CEP-modified protein is readily apparent in the white matter and extends into the grey matter throughout the cortex in cases of autism (C). A similar area in an age-matched control case shows no CEP (A). Following adsorption with antigen, the staining is greatly reduced (D) when compared to the positive staining on an adjacent serial section (C). Scale bars $=50 \mu \mathrm{m}$.

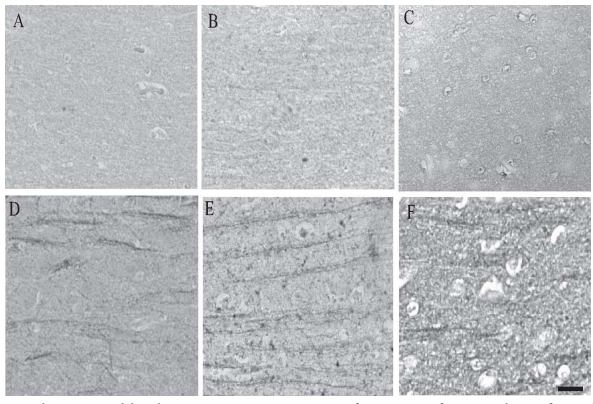

Fig. 4: The cellular processes in autism brain labeled with CEP-modified protein (D) also accumulate heme oxygenase-1 (E) and iso[4]LGE $\mathrm{LGrotein}_{2}$ adduct $(\mathrm{F})$. These markers are not present in specific structures in any corresponding controls (CEP-A, heme oxygenase-1-B, iso[4] $\mathrm{LGE}_{2}$-protein adduct-C). Scale bar $=50$ $\mu \mathrm{m}$.

Using Western blot analysis, a band around 200 $\mathrm{kDa}$ is seen to contain CEP-modified protein (Fig. 5). In striking contrast, a 17 year control shows no CEP immunoreactivity. Given that anti-CEP demonstrated extensive staining of neuronal processes, we suspect that this $200 \mathrm{kDa}$ band represented neurofilament heavy subunit (NFH). To further confirm the association of CEP and neurofilaments, an immunoprecipitation experiment was performed. The CEP antibody was used to immunoprecipitate CEP-modified proteins from autism brain homogenates. Probing the resultant blot with SMI32, an antibody against NFH, indeed shows an immunoreactive band at approximately $200 \mathrm{kDa}$, confirming that NFH is indeed a major target of CEP modification in autism brain (Fig. 5).

Levels of CEP and iso[4] $\mathrm{LGE}_{2}$-protein adducts in human blood were measured by competitive ELISA using polyclonal anti-CEP and anti-iso[4] $\mathrm{LGE}_{2}-\mathrm{KLH}$ antibodies respectively. We examined plasma from 27 patients with diagnosed ASD and 11 healthy controls with matched ages. There were no significant differences in the mean levels of CEP adduct between the plasma of ASD, $124.5 \pm 57.9 \mathrm{pmol} / \mathrm{mL}$, and the plasma of age-matched healthy controls, $110.4 \pm 30.3$ $\mathrm{pmol} / \mathrm{mL}, \mathrm{p}=0.45$. Nor were there statistically significant differences in the mean levels of iso[4] $\mathrm{LGE}_{2}$ protein adduct between ASD, $16.7 \pm 5.8 \mathrm{nmol} / \mathrm{mL}$, and controls, $13.4 \pm 3.4 \mathrm{nmol} / \mathrm{mL}, \mathrm{p}=0.088$.

Anti-CEP autoantibody titer in plasma from 26 ASD and 5 healthy controls was measured by ELISA. There were no significant differences in the mean levels of anti-CEP autoantibody titer between the plasma of ASD, $1.2 \pm 0.7$, and the plasma of age-matched healthy controls, $1.2 \pm 0.3, p=0.9$. Nor were there statistically 
significant differences in the mean levels of antiiso[4] $\mathrm{LGE}_{2}$ autoantibody titer between ASD, $1.3 \pm 1.6$, and controls, $1.0 \pm 0.9, \mathrm{p}=0.6$.

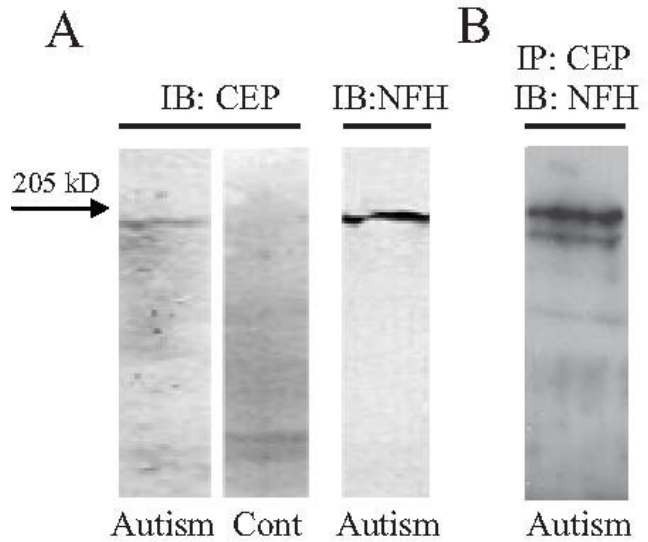

Fig. 5: Western blot analysis shows CEP-modified protein in autism and not in control brain, corresponding to the band recognized by a monoclonal antibody to NFH. Further confirming the association with $\mathrm{NFH}$, following immunoprecipitation with anti-CEP antibody, the blot was probed with SMI32 antibody specific for NFH.

A strong correlation exists in CEP and iso[4] $\mathrm{LGE}_{2^{-}}$ protein adduct autoantibody titer (Fig. 6), $\mathrm{R}=0.76, \mathrm{p}<$ 0.001 . Fig. 7 shows differences in levels of lipid oxidation protein adducts, grouped according to birth events of ASD patients with no events, born premature or other events such as C-section, cord wrapped and low birth weight.

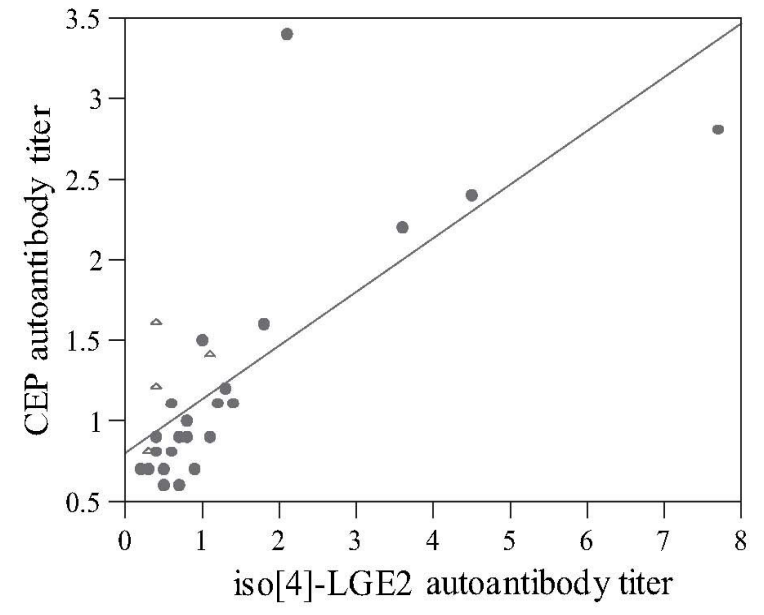

Fig. 6: Correlation between CEP and iso[4] $\mathrm{LGE}_{2}$ protein adduct autoantibody titer in human plasma from $\operatorname{ASD}(\lambda, \mathrm{N}=26)$ and normal controls $(\triangle, n=5), R=0.76, p<0.001)$.
A number of inflammatory and neurodegenerative disorders have been linked with protein modification by reactive nitrogen species including ocular inflammation, atherosclerosis, retinal ischemia, lung infection, cancer, Parkinson's disease, and Alzheimer's disease ${ }^{[20]}$. Measurement of $\mathrm{NO}_{2} \mathrm{Tyr}, \mathrm{a}$ posttranslational modification of proteins generated by reactive nitrogen species, serves as a quantitative index of nitrative stress in vivo. In this study, there were no differences between the ratio of $\mathrm{NO}_{2} \mathrm{Tyr} / \mathrm{Tyr}$ in plasma from $27 \mathrm{ASD}$ patients $(7.81 \mathrm{E}-06 \pm 3.29 \mathrm{E}-06)$ and that from 11 healthy controls $(7.87 \mathrm{E}-06 \pm 1.62 \mathrm{E}-06)$ (data not shown).

Birth Events and iso[4]LGE ${ }_{2}$ Immunoreactivity

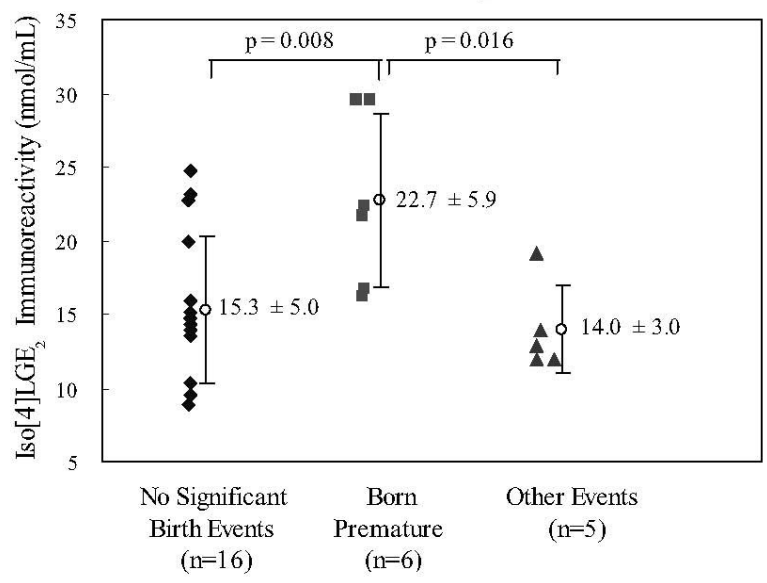

Fig. 7: Iso[4] $\mathrm{LGE}_{2}$-protein adduct immunoreactivity grouped according to birth events of ASD patients.

\section{DISCUSSION}

There is ample evidence of oxidative injury in autistic peripheral tissues ${ }^{[41,42]}$, however, there is little direct evidence for oxidative injury in the autistic brain. It is increasingly recognized that autism is primarily a neurodevelopmental disorder $\left.{ }^{[16,} 18,20\right]$ which may involve substantial neuronal loss in more than one brain regions ${ }^{[43,44]}$. Given that oxidative stress is implicated in neurodegeneration in many neurodegenerative diseases $^{[45]}$ and that the developing brain appears at increased risk for oxidative damage because of an immaturity of antioxidant defenses ${ }^{[46]}$, it is of major impact to determine whether there is oxidative injury in autistic brain. In this study, we present experimental evidence of oxidative damage in the autistic brain, primarily in the white matter, in the form of increased levels of lipid derived oxidative protein modifications, 
i.e., CEP and iso[4]LGE $\mathrm{LG}_{2}$-protein adducts, and heme oxygenase- 1 .

Lipid peroxidation is a well-established mechanism of cellular injury induced by elevated oxidative stress which results in the production of lipid peroxides and their byproducts that lead to the loss of membrane functions and integrity. In view of the high omega-3 poly unsaturated fatty acid (PUFA) content of the brain, it is likely that these fats participate in brain biochemistry, physiology and functioning; and may play a role in some neuropsychiatric diseases and ageing. However, the measurement of peroxidation products of free PUFA such as MDA, HNE or lipid hydroperoxides, is limited by the relative instability of the analytes and their ready formation ex vivo ${ }^{[47]}$. We recently developed and characterized a specific method to detect CEP adducts as a reliable and sensitive dosimeter for local oxidative damage which was successfully applied to the study of oxidative damage in $\mathrm{AMD}^{[48,49]}$. CEP adducts are uniquely generated from only the oxidation of docosahexaenoate (DHA)containing lipids. DA is the most oxidizable fatty acid in humans. It is a minor lipid in most tissues but rich in specific regions of the brain and retina ${ }^{[50,51]}$. Therefore, the production and accumulation of CEP-protein adducts might be especially sensitive to oxidation and important in pathological processes in these tissues. The most noteworthy result of the present study is the discovery that significant CEP-staining is found in the white matter in every autism cases but is absent in any of the control cases (age-matched or older) examined, suggesting elevated oxidative damage in these brain regions in autism. Obviously, oxidative damage in white matter in autistic brain involves more than DHAcontaining lipid since there is also elevated level of iso[4] $\mathrm{LGE}_{2}$-protein adducts, an oxidative protein modification derived from arachidonate-containing lipids. More importantly, the notion of elevated oxidative stress in autistic brain is further supported by the increased expression of heme oxygenase- 1 , a widely used oxidative stress marker in various neurodegenerative diseases ${ }^{[19]}$. The induction of heme oxygenase-1, an inducible antioxidant enzyme, is likely a response to elevated oxidative stress, which indicates that the elevated oxidative damage as evidenced by increased CEP and iso[4] $\mathrm{LGE}_{2}$-protein adducts elicit functional consequences, e.g., by inducing an antioxidant response.

One particular interesting aspect of our finding is that these three oxidative stress markers demonstrate similar staining patterns with white matter being most intensely labeled. The striking threadlike pattern appears to be a hallmark of the autistic brain. White matter consists primarily of axons serving to connect different sections of the brain. In fact, anatomical studies revealed abnormal alterations in white matter in autistic brain: depending on specific regions, the white matter abnormalities in autism include smaller white matter volumes in some regions such as corpus callosum $^{[52,53]}$ but also dysregulation and larger white matter volumes in other regions such as cerebellum ${ }^{[54-}$ 58]. A more detailed and systematic study on CEP modification in autistic brain is thus warranted. Nevertheless, it is of interest to note that reduced functional connectivity, i.e., the degree of synchronization or correlation of the time series of the activation between the various participating cortical areas, appears to be a general characteristic of the neurobiology of neural system in autism since it occurs in executing tasks involving reasoning, language, and social judgment ${ }^{[40]}$, all the major symptom domains that define the syndrome of autism. The proximal biological causes of functional underconnectivity could be either in grey matter or white matter or both. Our finding suggests that oxidative damage to white matter may potentially contribute to the underfunctioning or disorganization of white matter tracts which could underlie the underfunctioning of the inter-regional communication process that make use of these tracts and result in functional underconnectivity.

In contrast to the brain, similar levels of CEP and iso[4] $\mathrm{LGE}_{2}$-protein adducts and autoantibodies against them were detected in blood from both autistic individuals and normal controls. However, a subpopulation consisting of patients born prematurely showed significantly elevated iso[4] $\mathrm{LGE}_{2}$-protein adduct immunoreactivity levels compared with patients with no birth events or other birth events. The relevance of this finding to the pathogenesis of autism is unclear. The possible generality of the phenomenon of elevated plasma iso[4] $\mathrm{LGE}_{2}$-protein adduct levels does warrant further investigation as a heretofore unrecognized consequence of premature birth or postnatal treatment protocols. Another interesting observation, that has no evident relevance to the pathogenesis of autism, is a strong correlation between anti-CEP and antiiso[4] $\mathrm{LGE}_{2}$-protein adduct autoantibody titers in plasma from 26 ASD patients and 5 normal controls. This suggests that the proclivity of an individual to develop an immune response to altered self protein is similar for a diverse structural array of immunogenic modifications. A number of inflammatory and neurodegenerative disorders that have been linked with protein modification by reactive nitrogen species including ocular inflammation, atherosclerosis, retinal ischemia, lung infection, cancer, Parkinson's disease, and Alzheimer's disease ${ }^{[50,51]}$. We used tandem mass spectrometry to measure plasma levels of protein nitrative products (nitrotyrosine) in plasma. We found no significant differences between ASD and controls. 
The exact mechanism of oxidative stress in the autism brain is not known. It may be due to increased production of pro-oxidants or neuroinflammation. Even though there is induction of heme oxygenase-1, a deficient antioxidant response could not be excluded at this point since it is possible that induction of antioxidant enzymes may not be sufficient to balance the elevated oxidative threats as is the case in $\mathrm{AD}^{[59,60]}$. Elevations of peripheral brain-derived neurotrophic factor $\mathrm{BDNF}^{[61]}$, which exerts potentially protective anti-oxidant influences in brain may represent another homeostatic reaction to excess oxidative stress during neurodevelopment.

Overall, it seems highly likely that oxidative injury of proteins in the brain would be associated with neurological abnormalities. Therefore, the development of an animal model of the autistic phenotype should aim to replicate the pervasive, characteristically localized, oxidative protein modifications that we have uncovered in the present investigation. Our discovery of these protein modifications in autistic brain not only support the notion that brain oxidative stress plays a role in autism, but also suggest an area of focus for future in-depth mechanistic studies on the potential involvement of $\mathrm{NFH}$ oxidative modification in the pathogenesis of under connectivity in autistic brain. An increased understanding of the extent and mechanisms of oxidative stress within the brain is needed, and is likely to lead to improvements in the treatment of autism.

\section{ACKNOWLEDGMENTS}

This research was supported by Alexander and Bo MacInnis, Autism Research Institute, and the National Institutes of General Medical Studies of the NIH through grant GM21249. Human tissue was obtained from the NICHD Brain and Tissue Bank for Developmental Disorders at the University of Maryland under contracts N01-HD-4-3368 and N01-HD-4-3383. We also thank Jane Pickett for her continuous support and advice.

\section{REFERENCES}

1. Kanner, L., 1943. Autistic disturbance of affective contact. Nervous Child, 2: 217-250.

2. Volkmar, F.R. and D. Pauls, 2003. Autism. Lancet, 362: 1133-1141.

3. Siegel, B., 1996. The world of the autistic child: understanding and treating autistic spectrum disorders. Oxford University Press, New York, pp: 351 .
4. Fombonne, E., 2002. Epidemiological trends in rates of autism. Mol. Psychiatry., 7 (Suppl 2): S4-6.

5. Grice, D.E. and J.D. Buxbaum, 2006. The genetics of autism spectrum disorders. Neuromolecular. Med., 8: 451-460.

6. Bailey, A., A. Le Couteur, I. Gottesman, P. Bolton, E. Simonoff, E. Yuzda and M. Rutter, 1995. Autism as a strongly genetic disorder: evidence from a British twin study. Psychol. Med., 25: 63-77.

7. Horvath, K. and J.A. Perman, 2002. Autism and gastrointestinal symptoms. Curr. Gastroenterol. Rep., 4: 251-258.

8. Sogut, S., S.S. Zoroglu, H. Ozyurt, H.R. Yilmaz, F. Ozugurlu, E. Sivasli, O. Yetkin, M. Yanik, H. Tutkun, H.A. Savas, M. Tarakcioglu and O. Akyol, 2003. Changes in nitric oxide levels and antioxidant enzyme activities may have a role in the pathophysiological mechanisms involved in autism. Clin. Chim. Acta, 331: 111-117.

9. Sweeten, T.L., D.J. Posey, S. Shankar and C.J. McDougle, 2004. High nitric oxide production in autistic disorder: a possible role for interferongamma. Biol. Psychiatry, 55: 434-437.

10. Chauhan, A., V. Chauhan, W.T. Brown and I. Cohen, 2004. Oxidative stress in autism: increased lipid peroxidation and reduced serum levels of ceruloplasmin and transferrin--the antioxidant proteins. Life Sci., 75: 2539-2549.

11. Dolske, M.C., J. Spollen, S. McKay, E. Lancashire and L. Tolbert, 1993. A preliminary trial of ascorbic acid as supplemental therapy for autism. Prog. Neuropsychopharmacol. Biol. Psychiatry, 17: 765-774.

12. Chez, M.G., C.P. Buchanan, M.C. Aimonovitch, M. Becker, K. Schaefer, C. Black and J. Komen, 2002. Double-blind, placebo-controlled study of Lcarnosine supplementation in children with autistic spectrum disorders. J. Child Neurol., 17: 833-837.

13. Kleijnen, J. and P. Knipschild, 1991. Niacin and vitamin B6 in mental functioning: a review of controlled trials in humans. Biol. Psychiatry, 29: 931-941.

14. Petropoulos, H., S.D. Friedman, D.W. Shaw, A.A. Artru, G. Dawson and S.R. Dager, 2006. Gray matter abnormalities in autism spectrum disorder revealed by T2 relaxation. Neurology, 67: 632-636.

15. Trottier, G., L. Srivastava and C.D. Walker, 1999. Etiology of infantile autism: a review of recent advances in genetic and neurobiological research. J. Psychiatry Neurosci., 24: 103-115. 
16. Courchesne, E., J. Townsend and O. Saitoh, 1994. The brain in infantile autism: posterior fossa structures are abnormal. Neurology, 44: 214-223.

17. Raymond, G.V., M.L. Bauman and T.L. Kemper, 1996. Hippocampus in autism: a Golgi analysis. Acta Neuropathol. (Berl), 91: 117-119.

18. Schumann, C.M. and D.G. Amaral, 2006. Stereological analysis of amygdala neuron number in autism. J. Neurosci., 26: 7674-7679.

19. Chung, M.K., K.M. Dalton, A.L. Alexander and R.J. Davidson, 2004. Less white matter concentration in autism: 2D voxel-based morphometry. NeuroImage, 23: 242-251.

20. McGinnis, W.R., 2004. Oxidative stress in autism. Altern. Ther. Health Med., 10: 22-36; quiz 37, 92.

21. Filipek, P.A., J. Juranek, M. Smith, L.Z. Mays, E.R. Ramos, M. Bocian, D. Masser-Frye, T.M. Laulhere, C. Modahl, M.A. Spence and J.J. Gargus, 2003. Mitochondrial dysfunction in autistic patients with $15 q$ inverted duplication. Ann. Neurol., 53: 801804.

22. Zoroglu, S.S., F. Armutcu, S. Ozen, A. Gurel, E. Sivasli, O. Yetkin and I. Meram, 2004. Increased oxidative stress and altered activities of erythrocyte free radical scavenging enzymes in autism. Eur. Arch. Psychiatry Clin. Neurosci., 254: 143-147.

23. James, S.J., P. Cutler, S. Melnyk, S. Hernigan, L. Janak, D.W. Gaylor and J.A. Neubrander, 2004. Metabolic biomarkers of increased oxidative stress and methylation capacity in children with autism. . Am. J. Clin. Nutr., 80: 1611-1617.

24. James, S.J., S. Melnyk, S. Jernigan, M.A. Cleves, C.H. Halsted, D.H. Wong, P. Cutler, K. Bock, M. Boris, J.J. Bradstreet, S.M. Baker and D.W. Gaylor, 2006. Metabolic endophenotype and related genotypes are associated with oxidative stress in children with autism. Am. J. Med. Genet. B Neuropsychiatr. Genet., 141: 947-956.

25. Golse, B., P. Debray-Ritzen, P. Durosay, K. Puget and A.M. Michelson, 1978. Alterations in two enzymes: superoxide dismutase and glutathion peroxidase in developmental infantile psychosis (infantile autism) (author's transl). Rev. Neurol. (Paris), 134: 699-705.

26. Yorbik, O., A. Sayal, C. Akay, D.I. Akbiyik and T. Sohmen, 2002. Investigation of antioxidant enzymes in children with autistic disorder. Prostaglandins Leukot. Essent. Fatty Acids, 67: 341-343.

27. Ming, X., T.P. Stein, M. Brimacombe, W.G. Johnson, G.H. Lambert and G.C. Wagner, 2005. Increased excretion of a lipid peroxidation biomarker in autism. Prostaglandins Leukot. Essent. Fatty Acids, 73: 379-384.
28. Gu, X., S.G. Meer, M. Miyagi, M.E. Rayborn, J.G. Hollyfield, J.W. Crabb and R.G. Salomon, 2003. Carboxyethylpyrrole protein adducts and autoantibodies, biomarkers for age-related macular degeneration. J. Biol. Chem., 278: 42027-42035.

29. Poliakov, E., M.L. Brennan, J. Macpherson, R. Zhang, W. Sha, L. Narine, R.G. Salomon and S.L. Hazen, 2003. Isolevuglandins, a novel class of isoprostenoid derivatives, function as integrated sensors of oxidant stress and are generated by myeloperoxidase in vivo. FASEB J., 17: 22092220.

30. Money J., N.A. Bobrow and C.F. Clarke, 1971. Autism and autoimmune disease: a family study. J. Autism Child Schizophrenia, 1: 146-160.

31. Comi A.M., A.W. Zimmerman, V.H. Frye, P.A. Law and J.N. Peeden, 1999. Familial clustering of autoimmune disorders and evaluation of medical risk factors in autism. J. Child Neurol., 14: 388-394.

32. Sweeten T. L., S.L. Bowyer, D.J. Posey, G.M. Halberstadt and C.J. McDougle, 2003. Increased prevalence of familial autoimmunity in probands with pervasive developmental disorders. Pediatrics, 112: e420.

33. Connolly, A.M., M.G., Chez, A. Pestronk, S.T. Arnold, S. Mehta, R.K. Deuel, 1999. Serum autoantibodies to brain in Landau-Kleffner variant, autism, and other neurologic disorders. J. Pediatr., 134: 607-613.

34. Jyonouchi H., S. Sun and H. Le, 2001. Proinflammatory and regulatory cytokine production associated with innate and adaptive immune responses in children with autism spectrum disorders and developmental regression. J. Neuroimmunol., 120: 170-179.

35. Vojdani, A., A.W. Campbell, E. Anyanwu, A. Kashanian, K. Bock and E. Vojdani, 2002. Antibodies to neuron-specific antigens in children with autism: possible cross-reaction with encephalitogenic proteins from milk, Chlamydia pneumoniae and Streptococcus group A. J. Neuroimmunol., 129: 168-177.

36. Miyagi, M., H. Sakaguchi, R.M. Darrow, L. Yan, K.A. West, K.S. Aulak, D.J. Stuehr, J.G. Holleyfield, D.T. Organisciak, J.W. Crabb, 2002. Evidence that light modulates protein nitration in rat retina. Mol. Cell Proteomics., 1: 293-303.

37. Salomon, R.G., G. Subbanagounder, U. Singh, J. O'Neil and H.F. Hoff, 1997. Oxidation of LDL produces levuglandin-protein adducts. Chem. Res. Toxicol., 10: 750-759.

38. Sternberger, L.A., 1986. Immunocytochemistry. Wiley, New York, pp:

39. Nicholls, S.J., Z. Shen, X. Fu, B.S. Levison and S.L. Hazen, 2005. Quantification of 3-nitrotyrosine levels using a benchtop ion trap mass spectrometry method. Methods Enzymol., 396: 245-266. 
Am. J. Biochem. \& Biotech., 4 (2): 61-72, 2008

40. Halliwell, B., K. Zhao and M. Whiteman, 1999. Nitric oxide and peroxynitrite. The ugly, the uglier and the not so good: a personal view of recent controversies. Free Radic. Res., 31: 651-669.

41. Keller, F. and A.M. Persico, 2003. The neurobiological context of autism. Mol. Neurobiol., 28: $1-22$.

42. Chauhan, A. and V. Chauhan, 2006. Oxidative stress in autism. Pathophysiology, 13: 171-181.

43. Zhu, X., H.G. Lee, G. Casadesus, J. Avila, K. Drew, G. Perry and M.A. Smith, 2005. Oxidative imbalance in Alzheimer's disease. Mol. Neurobiol., 31: 205-217.

44. Gandhi, S. and N.W. Wood, 2005. Molecular pathogenesis of Parkinson's disease. Hum. Mol. Genetics, 14: 2749-2755.

45. Back, S.A., N.L. Luo, R.A. Mallinson, J.P. O'Malley, L.D. Wallen, B. Frei, J.D. Morrow, C.K. Petito, C.T. Roberts, Jr., G.H. Murdoch and T.J. Montine, 2005. Selective vulnerability of preterm white matter to oxidative damage defined by F2isoprostanes. Ann. Neurol., 58: 108-120.

46. Meagher, E.A. and G.A. FitzGerald, 2000. Indices of lipid peroxidation in vivo: strengths and limitations. Free Radic. Biol. Med., 28: 1745-1750.

47. Gu, X., S.G. Meer, M. Miyagi, M.E. Rayborn, J.G. Hollyfield, J.W. Crabb and R.G. Salomon, 2003. Carboxyethylpyrrole protein adducts and autoantibodies, biomarkers for age-related macular degeneration. J. Biol. Chem., 278: 42027-42035.

48. Skinner, E.R., C. Watt, J.A. Besson and P.V. Best, 1993. Differences in the fatty acid composition of the grey and white matter of different regions of the brains of patients with Alzheimer's disease and control subjects. Brain, 116 ( Pt 3): 717-725.

49. Alvarez, R.A., G.D. Aguirre, G.M. Acland and R.E. Anderson, 1994. Docosapentaenoic acid is converted to docosahexaenoic acid in the retinas of normal and prcd-affected miniature poodle dogs. Invest. Ophthalmol. Vis. Sci., 35: 402-408.

50. Smith, M.A., R.K. Kutty, P.L. Richey, S.D. Yan, D. Stern, G.J. Chader, B. Wiggert, R.B. Petersen and G. Perry, 1994. Heme oxygenase-1 is associated with the neurofibrillary pathology of Alzheimer's disease. Am. J. Pathol., 145: 42-47.

51. Takeda, A., M.A. Smith, J. Avila, A. Nunomura, S.L. Siedlak, X. Zhu, G. Perry and L.M. Sayre, 2000. In Alzheimer's disease, heme oxygenase is coincident with Alz50, an epitope of tau induced by 4-hydroxy-2-nonenal modification. J. Neurochem., 75: 1234-1241.

52. Courchesne, E., C.M. Karns, H.R. Davis, R. Ziccardi, R.A. Carper, Z.D. Tigue, H.J. Chisum, P. Moses, K. Pierce, C. Lord, A.J. Lincoln, S. Pizzo, L. Schreibman, R.H. Haas, N.A. Akshoomoff and R.Y. Courchesne, 2001. Unusual brain growth patterns in early life in patients with autistic disorder: an MRI study. Neurology, 57: 245-254.
53. Herbert, M.R., D.A. Ziegler, N. Makris, P.A Filipek, T.L. Kemper, J.J. Normandin, H.A. Sanders, D.N. Kennedy and V.S. Caviness, Jr., 2004. Localization of white matter volume increase in autism and developmental language disorder. Ann. Neurol., 55: 530-540.

54. Just, M.A., V.L. Cherkassky, T.A. Keller and N.J. Minshew, 2004. Cortical activation and synchronization during sentence comprehension in high-functioning autism: evidence of underconnectivity. Brain, 127: 1811-1821.

55. Koshino, H., P.A. Carpenter, N.J. Minshew, V.L. Cherkassky, T.A. Keller and M.A. Just, 2005. Functional connectivity in an fMRI working memory task in high-functioning autism. NeuroImage, 24: 810-821.

56. Just, M.A., V.L. Cherkassky, T.A. Keller, R.K Kana and N.J. Minshew, 2007. Functional and anatomical cortical underconnectivity in autism: evidence from an FMRI study of an executive function task and corpus callosum morphometry. Cereb. Cortex, 17: 951-961.

57. Castelli, F., C. Frith, F. Happe and U. Frith, 2002. Autism, Asperger syndrome and brain mechanisms for the attribution of mental states to animated shapes. Brain, 125: 1839-1849.

58. Mottron, L., J.A. Burack, G. Iarocci, S. Belleville and J.T. Enns, 2003. Locally oriented perception with intact global processing among adolescents with high-functioning autism: evidence from multiple paradigms. J. Child Psychol. Psychiatry, 44: 904-913.

59. Connolly, A.M., M. Chez, E.M. Streif, R.M. Keeling, P.T. Golumbek, J.M. Kwon, J.J. Riviello, R.G. Robinson, R.J. Neuman and R.M. Deuel, 2006. Brain-derived neurotrophic factor and autoantibodies to neural antigens in sera of children with autistic spectrum disorders, Landau-Kleffner syndrome, and epilepsy. Biol. Psychiatry, 59: 354363.

60. Miyazaki, K., N. Narita, R. Sakuta, T. Miyahara, H. Naruse, N. Okado and M. Narita, 2004. Serum neurotrophin concentrations in autism and mental retardation: a pilot study. Brain Dev., 26: 292-295.

61. Joosten, E.A. and D.A. Houweling, 2004. Local acute application of BDNF in the lesioned spinal cord anti-inflammatory and anti-oxidant effects. Neuroreport, 15: 1163-1166. 